\title{
Power Tillers for Demining in Sri Lanka: Participatory Design of Low-cost Technology
}

\author{
Cepolina Emanuela Elisa \\ University of Genova \\ Italy
}

\section{Introduction}

There is increasing consensus on the fact that landmines heavily affect the development of contaminated countries and that mine action activities need to be integrated into general development initiatives.

There is also general acknowledgment that machines have fallen short of expectations: only few are actually employed in the field and are often down for maintenance, waiting for spare parts or for experienced technicians to fix them coming from abroad.

These reasons are at the base of the idea of adapting commercially available power tillers to demining applications. Different modules attachable to the powertiller, modified to be the tractor unit, have been designed in a participatory way together with deminers. In fact, we believe that involving deminers in the whole design process would allow them to get familiar with the innovation process, which is a key component of the development process, and would help to create a machine closer to real needs, made of materials available locally and therefore with greater chance of success.

T) The project presented here therefore focuses on the participatory design and development of a new small machine for helping to remove landmines in the Vanni region in Sri Lanka, whole work encompasses the creation of four modules: tractor unit, ground processing tool, vegetation cutting tool, and the control unit to drive the machine from the safe distance of $20 \mathrm{~m}$

\& The tractor unit is the power tiller modified to resist possible explosions of landmines underneath and adapted to the remote control, while the ground processing tool is the means by which landmines are lifted up on the soil surface to facilitate later hand removal by deminers. The ground processing tool is placed on the front of the machine, to allow of landmines to be removed before the tractor unit passes over them. The vegetation cutting \$ module can be attached on the front of the machine when vegetation is too thick for the machine to pass through. It is powered by the power tiller engine and is supported by the same supporting frame of the ground processing tool.

Ф This chapter analyses the currently available cost-effective technologies on the demining market, before presenting the power tiller idea and the participatory methodology used for

Source: Humanitarian Demining: Innovative Solutions and the Challenges of Technology, Book edited by: Maki K. Habib, ISBN 978-3-902613-11-0, pp. 392, February 2008, I-Tech Education and Publishing, Vienna, Austria 
designing it, followed by a detailed description of the four modules. It finally ends with further work, acknowledgments and conclusions.

\section{Mine Action in Development: Possibilities for participatory Design of Low- cost Technology}

The Geneva International Centre for Humanitarian Demining (GICHD) has recently launched a new research project, seeking to assist government officials, donors and mine action and development practitioners to better link mine action with development (LMAD). It is seen as essential that mine action and development initiatives are effectively coordinated at all levels in order to align mine action with national and local development priorities, incorporate mine action within national development plans and budgets, increase stability of mine action funding and provide more effective mine action and development interventions (Naidoo, 2007).

After conflicts, countries generally transit through three main phases: immediate postconflict stabilisation, reconstruction and traditional development with assistance from international donors and financial institutions. Even if in some cases, as Sri Lanka, dormant conflicts resume, slowing the transition through the phases, the development stage is eventually achieved.

Mine action activities take place along the whole process, targeting different aims in different phases. During the development phase, mine action is more likely to concentrate on community priorities, as main roads and other infrastructure have already been cleared and re-opened. In many countries this phase lasts for a long time. "What is certain is that mine action programmes in heavily contaminated countries will almost certainly not be able to declare victory in the short-to-medium-term."(Filippino, 2005).

Therefore, mine affected countries would need to equip themselves adequately for the long haul and programmes have to assess their performance in terms of results that make a positive difference to people's lives. In fact, although we know that millions of people living in 79 countries are affected by landmines (ICBL, 2006), the size of the global landmine problem is not yet well defined, being missing indicators measuring indirect impacts of landmines on people's lives. The post-conflict impact of landmines on development goes far beyond the direct and cruellest effects on human lives and health; other important indirect effects are caused by the fact that landmines create obstacles to free movement within affected areas, posing restrictions on people's freedom and ability to access basic needs such as food, shelter, clean water, hygiene, transport, education and work, compromising their human development.

Moreover, the threat posed by landmines is only one among many others that people living in affected countries are facing everyday, such as the threats posed by HIV, malaria, road accidents, and so on. Therefore, approaching the landmine problem in relation to all the others, in the wider context of development, would lead to the possibility of being able to deal with it for longer and to do it in a more effective manner. In fact, donors' attention to demining is decreasing: donors are showing fatigue having spent money in demining activities for years without having seen the results promised. The goal of having the world free of mines by 2010, is no longer realistic due to the slow and often incomplete nature of demining operations. 
Approaching the landmine problem in the wider context of development suggests a change in the methodology to design humanitarian demining technologies.

That science and technology play a pivotal role in the development process has been shown by the exponential rate of growth of living standards after the industrial revolution. After $1820,1 / 6$ of the world population achieved high-income status through consistent economic growth and technology has been the main driving force behind. "I believe that the single most important reason why prosperity spread, and why it continues to spread, is the transmission of technologies and the ideas behind them"(Sachs, 2005), says Jeffrey Sachs, special advisor to the former UN secretary-general Kofi Annan.

In fact, one of the main differences between rich and poor countries is in their tendency to innovate; in poor countries inventors often do not have the incentive to invent because they know they will not be able to recoup the large fixed costs of developing new products. Even if the diffusion of technologies developed else where can help development by bringing to poor countries new ideas and tools, often technologies are not designed taking poor countries' ecological conditions into account and therefore are not suitable to tropical or arid or mountain environments found in these countries.

Indeed, rapid economic development would require that technical capacities suffuse the entire society, from the bottom up. In any developing countries, home-grown technologies would be needed to adapt the global process to local needs in areas ranging from energy production and use, construction, natural hazards mitigation, disease control and agricultural production as well as humanitarian demining.

Therefore, a new methodology to design technology in a participatory way together with local end-users is here presented and used to design a new mechanical system for helping humanitarian demining operations in Sri Lanka.

Specifically, we propose to develop low-cost technology using local resources adapting already available agricultural technology to demining tasks; leveraging mature technology would allow the exploiting of local knowledge already acquired through decades of use. Skills acquired in modifications of agricultural technologies to demining applications, could be used later on to increase agricultural production. Technological innovation in the field of agriculture is one of the major contributors to development.

This participatory approach would empower local communities by increasing their technical knowledge while making use of their own experience and skills.

\section{Mechanical Demining Equipment: Field Experience of Machines Available on the Market and Analysis of Low-cost Locally Made Ones}

A research we carried out in 2004, funded by the European support measure EUDEM2, showed that the current state of field use of off the shelf machines was limited, especially if compared with sensor technologies. The aim of the study was to ascertain the current demining technologies available in various contaminated countries and end-users feedback about them; the audience targeted was both the researchers approaching the problem of designing new demining technologies and NGO's workers in affected countries. During the three months spent in the field, we visited nine organizations working in four different countries: Mozambique, Namibia, Sri Lanka and Cambodia (Cepolina et al., 2004).

While gathering various data, we asked nongovernmental organization logisticians about the maintenance costs of technologies in terms of the operating cost, salary of operators, 
downtime due to mechanical failures, time between failures and cost to repair failed machines. Generally, we found a huge difference between the maintenance costs of a machine and that of a sensor. Taking as an example our data gathered in Mozambique, the maintenance costs per month of a machine in use at an organization were US\$530 while the cost for maintaining a sensor was \$194. These calculations do not even take into consideration the cost of training, which lasts for 25 days for a machine and less than one day for a sensor (Cepolina, 2006).

Thus, we believe high maintenance costs are one of the key factors behind the low adoption rate of machines by demining organizations. In our calculations, the high maintenance expenses were primarily due to the excessive cost to repair machines, multiplied by the high frequency of machine failures. We concluded that demining machines available on the market are complex systems that have not been conceived by the deminers who use them; nor have most machines been developed specifically for the environment in which they are being used. However, the organizations visited had few resources invested in personnel and workshops for mechanical technologies, each using between zero and two machines. An exception was represented by one organization visited, employing nine different mechanical technologies. All machines were adapted from mature technologies modified with locally available material in a specialized workshop. During the summer of 2006 we visited another demining programme in Georgia and there were many machines in use, covering all operations. In this case as well, the presence of a specialized team of mechanics helped daily with the maintenance of machines.

By using the following scheme, the cost-efficiency of such locally developed machines is much higher than the ones that were developed elsewhere.

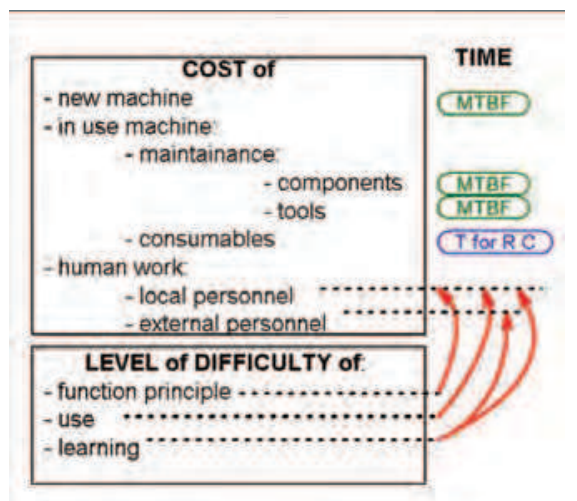

Fig. 1. Cost-efficiency paradigm

This is due to the fact that machines developed locally have initial lower cost, shorter down time and lower repairing cost. Among such mechanical technologies were machines built upon construction equipment, using off-the shelf attachments such as vegetation cutters or sifters armoured when necessary, off the shelf trim cutters, locally produced rollers designed to mechanically activated mines when towed on suspected areas as well as rakes and ground scrapers. 
However, it is shown that investing in machines requires also investments in maintenance capabilities. In fact, a new philosophy has recently proven to be successful: some machines are currently delivered with a mobile workshop and the technicians in charge of taking care of the maintenance for the whole duration of work. While this approach can be very effective, it does not empower local communities as there is no knowledge transfer; therefore is more suitable for emergency responses than for development phase.

Among mechanical technologies available on the market and documented in the Mechanical Demining Equipment Catalogue 2006, published by the GICHD, the cheapest is Tempest Mk V. It costs 120,000 USD and is classified as multi-tool system presenting a range of attachments from vegetation cutter to ground engaging head. It is produced in Cambodia in the Development Technology Workshop using local materials and facilities. Although not adapted from any existing technology, it is designed to incorporate materials that are locally purchased within developing mine affected countries as Cambodia and to be easily repairable without factory support. Moreover, DTW offers an upgrade package which extend the normal working life of Tempest, as all machines can be completely stripped down and disassembled before being refurbished with any new factory modifications or equipment used. The upgrade package costs $20 \%$ of the original purchase price.

Generally, the cost of machines increases as the size increases, mini and medium flail systems weighing from 3000 to $14500 \mathrm{~kg}$ costing between 220.000 and 300.000 USD, other than Tempest multi-tools weighing from 4700 to $7500 \mathrm{~kg}$ costing between 200.000 and 425.000 USD and Tillers weighing approximately $50.000 \mathrm{~kg}$ costing around 1.500.000 USD.

Unfortunately, the price of many machines presented in the Catalogue is not reported, making it difficult to analyse the difference between mechanical demining technologies adapted from mature technologies such as tractors or construction equipment and other technologies. Nevertheless, among advantages of machines adapted from other technologies is often mentioned the availability of spare parts from local dealers of the manufacturing company producing the prime mover.

\section{Power Tillers for Demining in Sri Lanka}

Given that every mine problem is unique and strictly linked to the area where it occurs, the research focuses on one particular region of Sri Lanka: the northern area of Vanni. Designing a technology for operation in a specific region helps to concentrate efforts on a well-defined problem; moreover, it allows local deminers to be involved in a project from which they will benefit and to exploit the knowledge they have acquired over long years working in the field.

We have chosen Sri Lanka for several reasons: people are generally well educated (having typically attended 10 years of school), enthusiastic, and willing to work and learn new skills. Additionally, at the time the project started, the country was facing an immediate postconflict situation in which people were strongly involved in rebuilding the country. Unfortunately after presidential elections of November 2005, the situation deteriorated rapidly: the fragile cease-fire agreement signed in 2002 collapsed in everything but name due to almost daily violence. Although the ongoing conflict creates more difficulties in logistics and communications, we believe that a participatory approach to the design of a new technology could assume an important role in support of the efforts to achieve peace. 
New tools not involving face to face communication were thought and used for design phases prior to the effective prototypization in loci.

A one-month trip to the Vanni region in Sri Lanka was organized in January-February 2005. The trip was aimed at establishing contacts, deepening knowledge of the local environment and improving communication skills to make the participatory contribution more effective. We interviewed groups of deminers to start the research in the right direction, better understand local needs and establish a reciprocal trust between local people and expatriates coordinating humanitarian operations in Sri Lanka. Most notably, in the field information was gathered by working on the functional requirements for a system of small, light and cheap demining machines to be used for working close to the deminers. The need of such a system arose from the study conducted in 2004 in collaboration with EUDEM2. When deminers were asked about their preferences for new machine technology, they expressed a strong desire for new machines that were small, light and cheap. They wanted them to help in the most boring/difficult parts of their job, particularly cutting vegetation and processing the ground, specially the hardest one, currently scarified using a simple rake called heavy rake, to remove the soil hiding mines.

Based on these findings, we suggested adapting power tillers to demining applications. Power tillers are widely used and commercially available in Sri Lanka, and their secondhand market is largely spread. They are easy to transport as they are small and light, and they are available with different types of engines. The most powerful one (approximately 14 $\mathrm{kW}$ ) is sturdy enough for our task, being Vanni region soil either sandy or soft because of alluvium type.

Power tillers, also known as walking tractors, two-wheel tractors or iron buffalos have a great importance in their nations' agriculture production and rural economies. They not only have rotovator attachments but also moldboard and disc-plow attachments. Seeders, planters, even the zero till/no-till variety can be attached. Reaper/grain harvesters and micro-combine harvesters are available for them. Also very important is their ability to pull trailers with two plus ton cargoes.

The population of power tillers in developing countries is surprising high. China has the highest numbers that are estimated to approach $10 \mathrm{M}$, Thailand has nearly $3 \mathrm{M}$, Bangladesh has over 300,000 Sri Lanka 120,000, India 100,000 Nepal 5,500. Parts of Africa have begun importing Chinese tractors and Nigeria may have close to 1,000 (Wikipedia, 2007). Numbers are likely to increase as the availability of draft animals is reducing.

By adapting power tillers to demining application we intend to increase the number of these machines available to rural villages. After operations they can be re-converted to original agricultural use and exploited for increasing agricultural production.

As suggested by the NABARD association (NABARD, 2007), to achieve the desired average farm power availability of $2 \mathrm{~kW} / \mathrm{ha}$, necessary to assure timeliness and quality in field operations in India, agro services centers could be established. There, machinery could be provided on custom hire basis to the small and medium farmers who cannot afford purchasing their own machinery as and when it is needed. In the same manner, in parallel to agricultural machines, the agro service centers could provide also machines for demining applications, based on agricultural machines. They could develop locally modifications required to effectively address the demining problem, hire these machines and provide assistance. 


\section{The Snail System}

The originality of the project lays in the fact that end-users are involved in the whole design and development process of the machine.

We believe that is really important to understand the context in which a technology will work and the consequences the technology can cause on the society that will use it.

Therefore, in parallel to the technical work on the machine, we are also researching into the relationship between landmines, humanitarian demining technologies and development and we are proposing a new methodology for designing mechanical technologies for humanitarian demining in a participatory way together with deminers having worked in the field for a long time.

A first concept of the system to design technology in a participatory way, termed Snail System, has been elaborated and used.

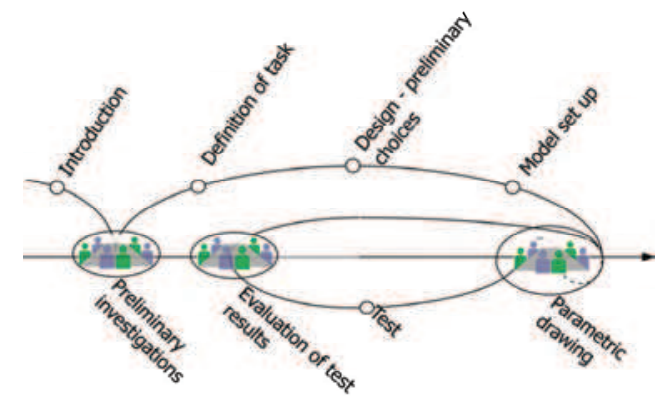

Fig. 2. Snail system

The Snail System is an iterative design methodology allowing a progressive involvement of end-users in the design process. Snails are lines connecting subsequent steps of the design process that develop along a straight line indicating work progress.

Meetings with end-users happen along the straight work progress line. Every decision is made with end-users; only studies prior to these decisions, such as the preparation of possible choices, simulations and calculations, are carried out by researchers and later presented to end-users.

The design evolves along all the traditional steps including the creation of models, as tools to support design decisions making.

Models can be either mathematical, digital mock-ups, when prepared in university laboratories or very simple models made with material ready available, also called crap-ups (Roth, B., 2006), when done in the field together with end-users. The idea is making prototypes quickly, even very rough ones, to get the ideas flowing and to find out which direction seems most fruitful. Test is done by discussing together with all people involved in the subject, at all different levels, from locals dealing with the problem everyday, to researchers living in western countries. Learning by mistake is very effective, especially at early stages of the design process.

Each Snail represents a work module necessary to carry out the main package of the total work for the project. The workflow of technology design is represented by Snail lines, as often it is iterative; the design process is repeated until a satisfactory result is reached. 
Together with end-users, we have tried to involve many other possible contributors into the design process of the machine to make it more effective. People working for manufacturing companies of components we used, international demining experts, various representative of NGO's, people working in garages were agricultural machines are fixed and researchers of various universities gave their precious contribution to the project.

In order to involve local end-users into the design and development of the new machine, participatory techniques have been used, such as ranking and rating tools.

When not able to meet end-users or other researchers and experts contributing to the work face to face, the project website (http://www.dimec.unige.it/PMAR/demining/) was used as communication channel. There, power point presentations have been linked to the main pages describing the work and instructions on how to add comments or modifications to them using collaborative online tools provided by Zoho services (http://www.zoho.com/) were added. When modifications are made anonymously they are visible in real time in website pages, directly contributing to the work.

\section{Participatory Agriculture Technology (PAT) for Humanitarian Demining Project}

Therefore, the main goal of the project is to adapt agricultural machines to assist humanitarian demining operations in the Vanni region of Sri Lanka.

Deminers asked for their preferences during group interviews, expressed a strong desire for new cheap and light machines, small enough to be fitted in the back of a small truck. They want machines to help in the most boring/difficult parts of their job, particularly cutting vegetation and processing the ground, specially the hardest one, currently scarified using the heavy rake. In fact, no metal detectors are employed by Norwegian People's Aid (NPA), the NGO partner of the project with the University of Peradeniya in Sri Lanka, as soil is ferrous and mines have very low metal content; instead, ground is excavated at the depth of $100 \mathrm{~mm}$, specified by local authorities, to expose to eye sight buried landmines. Two simple rakes with handler extended to $2 \mathrm{~m}$ are used: light rakes to remove loose soil and hard rakes to process more compact and deep soil. Vegetation is manually cut with simple gardening tools like saw, sickle and shears.

Therefore, the target of the project is to develop a modular system using as core module a power tiller and equipping it with modules specialised for ground processing and vegetation cutting, able to process the soil and make demining operations with the excavation tools currently used by local deminers faster. A special end-effector to process the soil and bring mines up to the soil surface is being designed. Each machine can be considered a semi-autonomous system, helping a single deminer in his work, and a certain number of machines can be controlled automatically to perform area-reduction operations, working as a multi-agent system. Deminers will always assist machines: once a mine is found and lifted up on the soil surface by the special end-effector, a deminer can remove the mine manually. Manual mine removal has been introduced in order to lower the complexity and cost of the machines, as well as to allow a quicker integration of machines in operational procedures.

Between small agricultural machines available in Sri Lanka we have chosen to employ power tillers, as they are very common and widely used, being one of the most important multi-purpose agriculture and transport vehicles in the country. 
A modular top-down design approach was chosen. Starting from the task, defined by deminers, the mechanical modules able to accomplish the work were conceived. The project involves the mechanical design of three modules: tractor unit, ground processing tool and vegetation cutting tool.

The project foresees also the implementation of the control of the machine that needs to be operated remotely, when Unexploded Ordnance (UXO) and fragmentation Anti Personnel (AP) mines are known to be present.

The overall essential requirements the machine has to satisfy are:

- reliability: $100 \%$ clearance

- $\quad$ safety of operator: $100 \%$

- depth of demining: $100 \mathrm{~mm}$

- $\quad$ width of clearance: $1200 \mathrm{~mm}$

- $\quad$ speed of clearance: higher than manual

- $\quad$ types of mines: small plastic blast-type AP mines

- $\quad$ cost: $20.000 €$

- $\quad$ remote control distance: $20 \mathrm{~m}$

Considered mines are small because they are between the less harmful existing ones, containing up to $50 \mathrm{~g}$ of explosive only. UXO and fragmentation mines are also present, especially Claymore types, but only in certain known minefields. The machine is specifically designed to be proof against AP blast mines and to resist damages caused by fragmentation devices.

Cost is one of the main points of the project, being one of the major causes of poor adoption of machines into demining programmes. The price of $€ 20.000$ does not include the research and developing cost and is equally divided between the modules and the control.

A preliminary test was performed in order to get physical understanding of the effects of a mine explosion on the power tiller, when a mine is activated by one wheel.

Results (Salvi \& Cepolina 2005) were encouraging as the power tiller chassis was not considerably damaged after four explosions, suggesting that only a thin steel plate, possibly presenting small holes in order to lower its weight, could be used to protect it. Steel open cage wheels deformed after the explosion and lost blades. We believe that damages to them were limited by their open structure allowing part of the blast wave to expand in air. Upon test results the implementation plan to carry out the project was developed.

The implementation plan foresees the development of a first prototype in the workshop of the University of Genova. After testing it in conditions similar to the ones found in Sri Lanka, the experience gained and lessons learnt will be used to develop a second prototype in a local workshop in the Vanni region of Sri Lanka. 


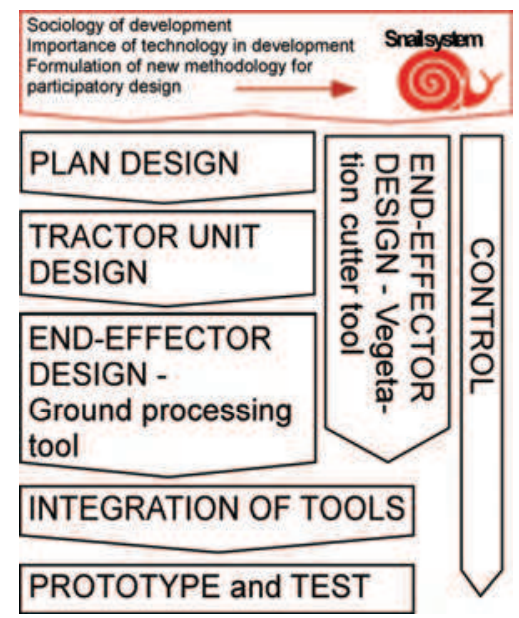

Fig. 3. Implementation plan.

\section{Tractor Unit}

Pursuing the idea of employing mature technologies already available in the country and particularly small agricultural technologies, as basic machine, the suitability of the power tiller as tractor unit was verified first.

Between the main reasons leading to the idea of using the power tiller, there were its small dimensions and its low weight. In order to process the ground in front of a deminer, the machine has to work in the demining lane, which in Sri Lanka is $1200 \mathrm{~mm}$ wide: $100 \mathrm{~mm}$ on each side are used for verification of working depth. In order to be transported easily to the minefield, the machine has to fit in the boot of the small ISUZU ELF trucks mostly used by NPA, carrying up to $2000 \mathrm{Kg}$ in $1,8 \times 5 \mathrm{~m}$ area. The weight and dimensions of one of the biggest powertiller available on the Sri Lankan market, produced in China by the Dongfeng Brand, the DF-12L model with 10kW engine are more than suitable.

The powertiller shown on the right hand side of fig. 4 is the one we have in the laboratory, on which we are working. It was produced in Italy in 1944 and presents similar characteristics to the one we would like to employ in Sri Lanka. We bought it second hand for $100 €$. After some work, it started running again.

Obviously, the speed of work of a power tiller is higher than the one of a manual deminer, calculated during time and motion studies held for the EUDEM2 survey equal to 0,0037 $\mathrm{m} / \mathrm{s}$. The working speed of a power tiller processing the ground with a milling tool can be considered equal to $0,2 \mathrm{~m} / \mathrm{s}$.

The cost of power tillers is low, especially in developing countries like Sri Lanka, where a $10 \mathrm{~kW}$ one can be bought for $€ 250, € 70$ if second-hand. 


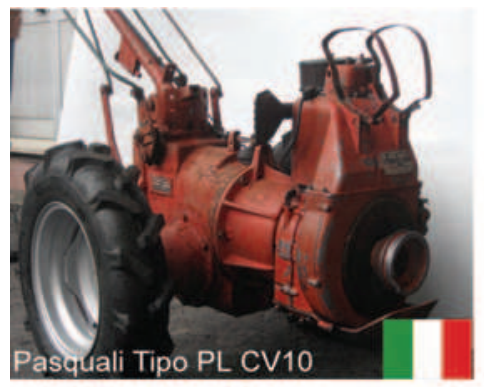

Overall dimensions:

L: $1900 \mathrm{~mm} \quad$ W: $770 \mathrm{~mm} \quad$ H: $850 \mathrm{~mm}$ Weight: $243 \mathrm{~kg}$

Travelling speed (I gear): $1.1 \mathrm{~km} / \mathrm{h}$

Engine: 10hp

Differential: yes

Gears: 3 forward, 3 reverse

Possibility to reverse handler: no Cost: $100 €$ secondhand

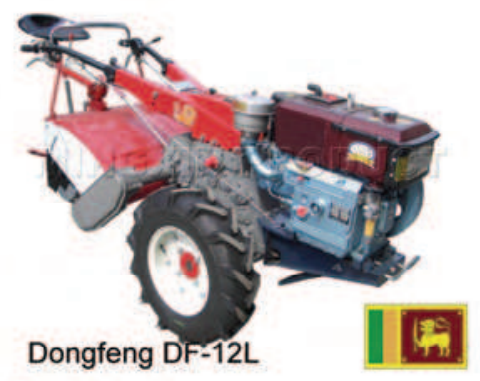

Overall dimensions:

L: $2680 \mathrm{~mm}$ W: $960 \mathrm{~mm} \quad H: 1250 \mathrm{~mm}$

Weight: $350 \mathrm{~kg}$

Travelling speed (I gear): $1.4 \mathrm{~km} / \mathrm{h}$

Engine: $12 \mathrm{hp}$

Differential: yes

Gears: 6 forward, 2 reverse

Possibility to reverse handler: no

Cost: $70 €$ secondhand, $250 €$ new

Fig. 4. Power tiller in use at the University of Genova Vs Power tiller available in Sri Lanka

The effective employment of a power tiller as tractor unit has to be evaluated considering functional requirements. Moreover, attention has to be paid at keeping the machine extremely simple, avoiding adding to a very simple basic unit such as the power tiller, complex modifications or tools.

Parameters have been identified that contribute to achieve extreme simplicity and effectiveness, referred at as Simpleffectiveness.

The features the tractor unit has to present in order to be Simpleffective are:

- forward/backward motion (traction)

- $\quad$ steering: $1 \mathrm{~m}$ curve radius

- $\quad$ energy supply to end-effectors

- $\quad$ stability

- $\quad$ assessment of ground processing depth

- $\quad$ mine disposal

- $\quad$ safety of operator

- $\quad$ shock wave protection for machine (and operator, in manual use)

The machine has to be mine resistant: it has to be designed to be proof against antipersonnel (AP) blast mines, while resisting damages caused by the fragmentation associated with UXO and anti-personnel fragmentation mines.

A first indicative analysis of the mobility and energy requirements suggested that the power tiller is suitable to the aim, with only little adjustments. In fact, power tillers present several gears, the number depending on the model, including at least one for going backward; steering can be achieved thanks to the differential gear. Moreover, part of the energy coming from the engine can be used for actuating the end-effectors through the power take off.

Generally, power tillers available in Sri Lanka do not have a battery on board, therefore one should be added to supply energy to the control unit. 
A rough estimation of the power required to push or pull an end-effector to process the ground at $100 \mathrm{~mm}$ depth, $1200 \mathrm{~mm}$ wide, in clay soil, at $0,1 \mathrm{~m} / \mathrm{s}$ working speed is $3 \mathrm{~kW}$. The power absorbed by a vegetation cutter tool $120 \mathrm{~cm}$ wide, like cutting bar, is $4 \mathrm{~kW}$.

While the vegetation cutting tool is certainly placed on the front of the power tiller to allow the machine to pass through thick vegetation, two different possible working configurations for the ground processing tool, designed to rake the ground and bring mines up on soil surface, have been identified: one with the ground processing tool at the back (G-P-B) and one with it on the front (G-P-F). The choice is subject to the evaluation of Simpleffective parameters values in the two cases.

A physical, a multi body and a 3DCAD model have been created to support design decisions, through simulations and tests.
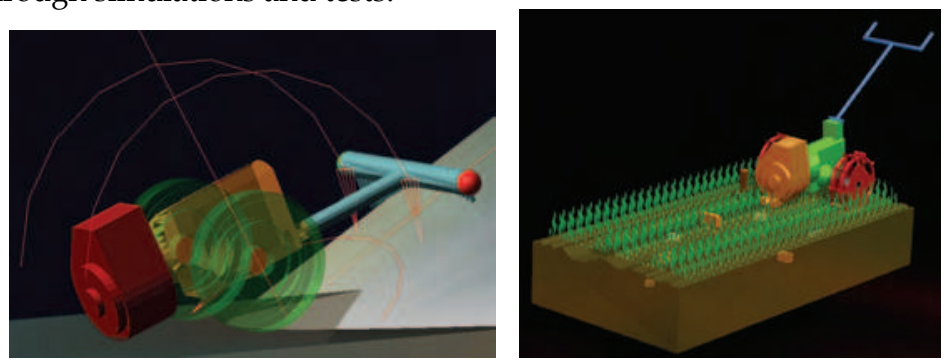

Fig. 5. Multi-body and 3DCAD models of power tillers

While the multi body model was aimed at assessing the stability of the two configurations under different load conditions, the physical model was aimed at supporting the test of the preliminary version of the tractor unit armouring to resist detonations of AP mines.

In fact, a way to protect the tractor unit from shock waves caused by the explosion of a landmine under a wheel was researched first.

Following the idea of modifying the power tiller as little as possible, it was chosen to protect the tractor unit by allowing the wheel to drop off when explosion occurred. The idea was that if physical connection was interrupted, the shock wave transmission to the axle and to the power tiller drive train should be significantly reduced. Moreover we believed that damages to the wheel should be reduced as well.

Therefore, breakable connections to be placed between the wheel and the flange were designed for withstanding normal working load conditions while breaking when an explosion occurred. The idea was to interrupt the transmission of the shock wave from the wheel touching the ground to the power tiller axle and subsequently to the gear train. To connect modern wheels to the axle of the old power tiller it was necessary to design a supporting flange. The breakable connection is therefore designed to be fastened to the flange connected to the axle on one side and to the wheel on the other side (see fig. 6). The breakable ring is made of cast iron ASTM 30 class. 


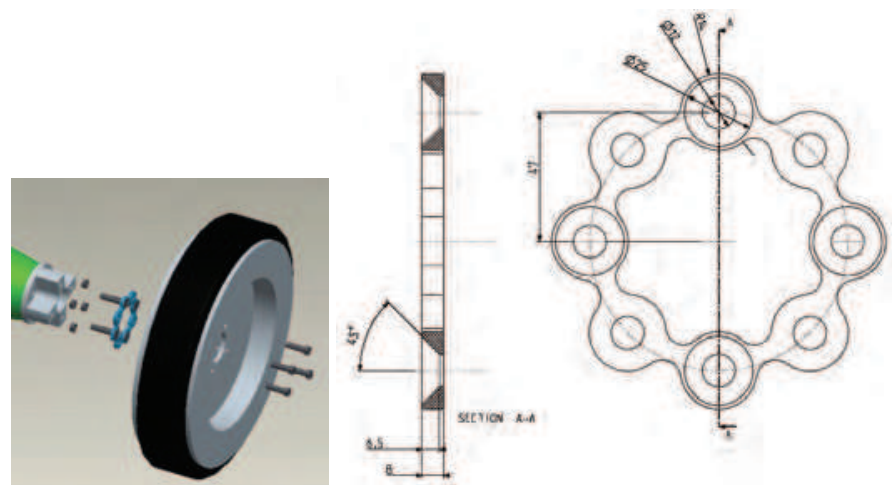

Fig. 6. Assembly of wheel, breakable ring and flange and technical drawing of breakable ring

In case of explosion and fracture of the ring, most likely to happen along the bridges, a new ring could be replaced simply by screwing it into the flange first and into the wheel later.

A blast test was organized in May 2006. It took place under the supervision of Danilo Coppe, one of the major explosive experts in Italy, in an open air cave near to Fornovo, Parma. The aim was to verify the suitability of the preliminary version of the tractor unit armouring, based on the concept of the breakable connection, to resist detonation of AP mines. Together with the breakable ring, two other breakable connections were tested, simply constituted by two sets of screws, fastening the wheel to the flange, presenting double and single cuts along their body.

Wheels tested were common agricultural pneumatic wheels, filled in with two different types of elastic gums: GoFill tyre filler and GoSeal tyre sealer, kindly provided by GoGomma, who has also agreed to provide a workshop in the field in Sri Lanka with second hand machines necessary to fill in every kind of wheel with those special elastic gums, in case of positive test result.

Five explosions took place, with landmines respectively underneath:

- $\quad$ wheel filled in with GoFill

- wheel connected to the axle with breakable ring

- $\quad$ wheel connected to the axle with screws with double cut

- $\quad$ wheel connected to the axle with screws with single cut

- wheel filled in with GoSeal.

Unfortunately, results from tests were not as expected and the preliminary armouring is not currently suitable to protect the power tiller from damages caused by the detonation of AP landmines under wheels.

In fact, the principle adopted into the design of the breakable connections proved not to work; although the wheel connected through the breakable connection dropped off during two of the three explosions, the physical detachment happened after the blast wave was already passed through the connection and entered the power tiller structure, as it can be seen from measures recorded by the accelerometer placed on the axle.

The blast wave travelling at supersonic speed passed through the medium before it had the time to deform and break. Nevertheless, the breakable connection worked at reducing the total energy transmitted by the blast wave to the power tiller, by filtering waves at high 
frequency. Therefore, the breakable connection designed acted more like a high frequency filter than a low frequency filter, as expected.

The wheel rims got damaged almost in the same manner after each explosion except for the second, when the mine was not placed directly underneath but slightly internally. Therefore, no advantages of using the breakable connection are visible on wheel deformations. The reason for this could be that they remain physically connected to the power tiller until the breakable connection breaks, absorbing the same low frequency waves of the blast wave that pass through the power tiller structure.

Even if not damaged too much by each explosion, the wheel filled in with GoFill could not keep on working normally after the fourth explosion. The wheel filled in with GoSeal could definitely not keep on working after the first explosion.

The energy released by the blast wave and passed through the power tiller during the fifth explosion was 5 times less than the energy passing through the structure during the first explosion and 3 times less than the energy passing through the structure when the breakable connection was in place, see fig. 7. (Cepolina, 2007).
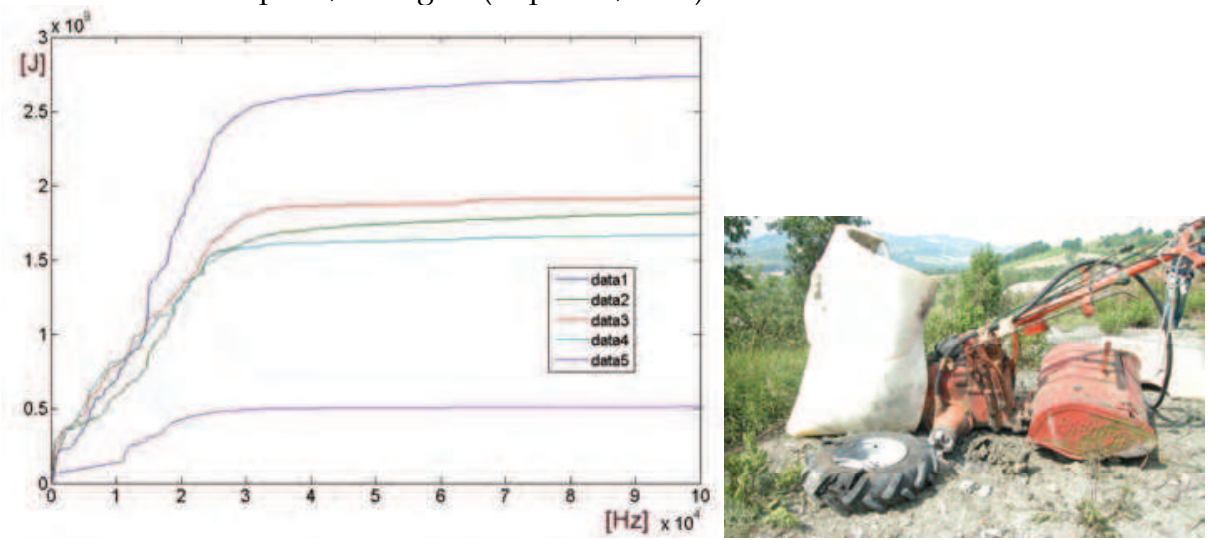

Fig. 7. Energy[J] versus frequency[Hz] passing through the power tiller in the five explosions (data1 refers to first explosion, data5 to the fifth); power tiller after fourth explosion

This suggests that pneumatic wheels filled in with air and liquid, in this case GoSealer, work at reducing the total energy transmitted to the structure better than solid wheels, filled in with GoFill. This result is in accordance with results obtained by Defence R\&D Canada (Hlady, S. 2006) who conclude that detonations under water-filled tires transferred more kinetic energy upwards than either the standard or runflat tires.

\section{Tractor Unit Re-design}

Upon these test results, we have decided to place the ground processing tool on the front of the machine.

This lowers the possibility to have an explosion under the machine as landmines should have already been removed when the machine passes. In order to increase traction, rubber tracks have been added connecting driven wheels to additional wheels supporting the 
ground processing tool on the front. Remote control of the tractor unit is then possible by actuating the two semi-axles through brakes, also added. Moreover, we believe that tracks could absorb part of the energy of an accidental explosion underneath by deforming flexibly.

Therefore, the system will work in the configuration shown in fig.8. having both the endeffectors on the front, the vegetation cutting tool supported by the same frame supporting the ground-processing tool.

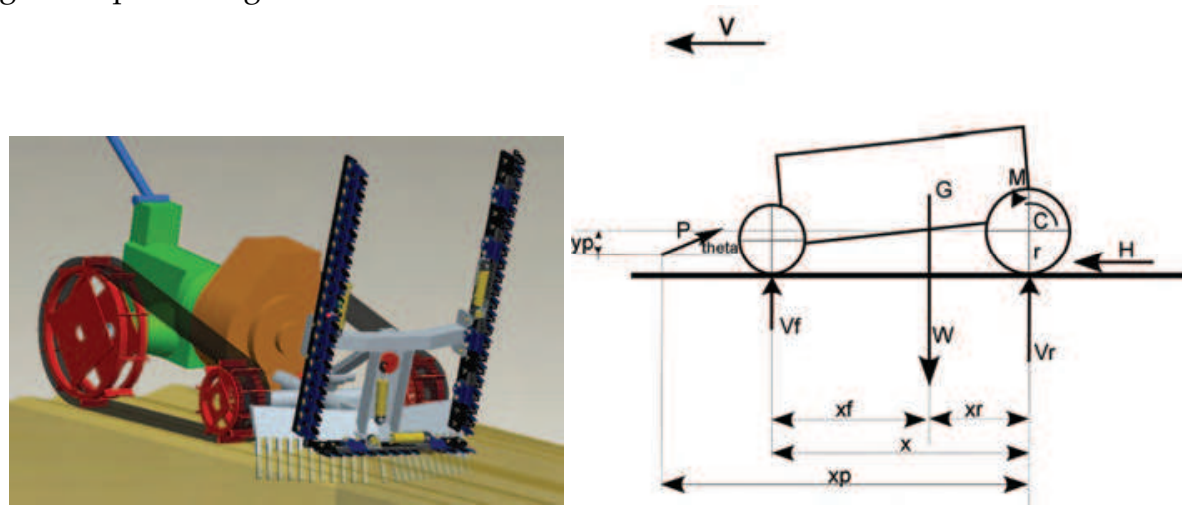

Fig. 8. Working configuration of the machine; first analytical model

The redesign of the tractor unit includes the design of the frame supporting the tools and the front wheels, the design of a tensioning system for the tracks, the choice of rubber tracks and the design of open cage wheels working as sprockets for the tracks. Moreover, it also includes the design of the front attachment for the tools.

The detailed design of these components has been done taking the power tiller Pasquali PL CV10 $(7.5 \mathrm{~kW})$ available at the University of Genova in mind. Although this is similar to the power tiller that will be used in Sri Lanka, modifications to the current design will be necessary and will be implemented in the field together with deminers before developing the second prototype in a local workshop, making use of the experience gained in Italy.

Modifying the power tiller by adding two additional front wheels and ground engaging tools at the front will affect weight transfer and the whole performance of the system.

First, a rough estimation of the implement draught force was made using two different approaches. From Agricultural Machinery Management Data, ASAE D497.5 FEB2006, published by the American Society of Agricultural and Biological Engineers (ASABE), the draft force, defined as the force required in the horizontal direction of travel for tools operated at shallow depths is given by eq. (1).

$$
D=F_{i} \cdot\left[A+B(S)+C(S)^{2}\right] \cdot W \cdot T
$$

Where, $\mathrm{D}$ is the implement draft, $\mathrm{F}$ id a dimensionless soil texture adjustment parameter whose value is given in ASABE tables, A, B and C are machine specific parameters, given in ASABE tables, $S$ is field speed, $W$ is machine width, $T$ is tillage depth. The value for the draft force necessary to push a tool, considered as a sweep plow in primary tillage, $1200 \mathrm{~mm}$ wide, at $100 \mathrm{~mm}$ depth, at $1.1 \mathrm{~km} / \mathrm{h}$, in fine textured soil, is approximately $2.5 \mathrm{kN}$. 
A second estimation of the draft force of approximately $2 \mathrm{kN}$ was obtained extrapolating data regarding a 19 tine scarifier fitted with $150 \mathrm{~mm}$ wide dart points (Kruger\&Palmer, 1982).

To analyse the performance of the new system, a simple analytical model (fig. 8) was created, in first approximation simply modelling the power tiller as a four wheel tractor. To take into the consideration the actual presence of tracks, the drawbar pull resulting from equilibrium equation was increased by a factor of four, obtained by analysing performances of the same tractor with wheels and with tracks (Macmillan, 2002).

Considering the hypothesis of constant velocity, soil reaction forces under the front and the rear wheels can be calculated from equilibrium equations (fig. 8):

$$
\begin{gathered}
V_{f}=W \frac{x_{r}}{x}-P \cos \theta \frac{r-y_{p}}{x}-P \sin \theta \frac{x_{p}}{x} \\
V_{r}=W\left(1-\frac{x_{r}}{x}\right)+P \sin \theta\left(\frac{x_{p}}{x}-1\right)+P \cos \theta \frac{r-y_{p}}{x}
\end{gathered}
$$

Where, the drawbar pull $\mathrm{P}$ is generally given by the difference between tractive force $\mathrm{H}$ and rolling resistance $\mathrm{R}$ :

$$
P=H-R
$$

While the tractive force $\mathrm{H}$ is generally associated with shear stress on soil, the rolling resistance $\mathrm{R}$ is associated with energy losses due to deformations of the wheel (elastic) and soil (plastic).

These forces can be theoretically calculated through complex expressions function of many parameters typical of the soil that are difficult to measure when not in the field and anyway differ from site to site. Nevertheless, from these formulas, a general understanding of the influence of design variable values on the force value can be obtained. Generally we have that the tractive force increases as the contact area between the machine and soil increases and as the total weight increases; rolling resistance increases as the dynamic weight on the wheel increases and as the wheel diameter decreases.

Using an empirical approach, instead, we are able to calculate the drawbar pull $\mathrm{P}$ as function of only one soil parameter, the cone index CI, measuring the resistance opposed by the soil to the penetration at the constant speed of $30 \mathrm{~mm} / \mathrm{s}$ of a circular cone of base area of $322 \mathrm{~mm}^{2}$ and cone angle of $30^{\circ}$. Another expression of $\mathrm{P}$, analogous to (4) is given in (5):

$$
P=V_{r} \cdot \psi-V_{f} \cdot \rho
$$

Where, $\mathrm{Vr}$ is dynamic weight on rear wheels, $\mathrm{Vf}$ is dynamic weight on front wheels, $\psi$ is the tractive coefficient for rear driving wheels, defined as ratio between the drawbar pull and the dynamic weight on driving wheels, and $\rho$ is the rolling coefficient for front wheels, defined as ratio between the rolling resistance and the dynamic weight on front wheels. Empirical expressions for $\psi$ and $\rho(7)$ and (8) have been found by Gee-Clough in 1978 for wheels on agricultural soil in function of a dimensionless number called the tyre mobility 
number $\mathrm{M}(6)$, function of the cone index $\mathrm{CI}$, weight on tyre $\mathrm{W}$, tyre width $\mathrm{b}$, tyre diameter $\mathrm{d}$, tyre section height $\mathrm{h}$ and tyre deflection under weight $\delta$.

$$
\begin{gathered}
M=\frac{C I \cdot b \cdot D}{W_{w}} \sqrt{\frac{\delta}{h}} \frac{D}{D+0.5 \cdot b} \\
\psi=\psi_{\max }\left(1-e^{-k \cdot i}\right) \\
\psi_{\max }=0.796-\frac{0.92}{M} \\
k=4.838+0.061 \cdot M \\
\rho=0.049+\frac{0.287}{M}
\end{gathered}
$$

By substituting eq.s (2) (3) in (5) we obtain an expression of the drawbar pull $\mathrm{P}$ in function of tractor unit design variables indicated in fig. 8.

$$
P=\frac{W\left[\psi\left(1-\frac{x_{r}}{x}\right)-\rho \frac{x_{r}}{x}\right]}{1-\psi\left[\sin \theta\left(\frac{x_{p}}{x}-1\right)+\cos \theta \frac{r-y_{p}}{x}\right]-\rho\left[\cos \theta \frac{r-y_{p}}{x}+\sin \theta \frac{x_{p}}{x}\right]}
$$

Therefore the drawbar pull of the tractor unit can be approximately estimated once the values of the following design variables are known:

$\mathrm{xr}$, distance of centre of gravity from rear wheel

$\mathrm{x}$, distance between axles (in tracks assembly, length of tracks)

$r$, radius of rear wheel

yp, vertical distance of point of application of $\mathrm{P}$ wrt $\mathrm{C}$

$\mathrm{xp}$, horizontal distance of point of application of $\mathrm{P}$ wrt $\mathrm{C}$

$\theta$, angle by which $P$ is inclined wrt the ground

and $\mathrm{W}$, total weight of power tiller plus implement.

The analytical model was used to choose the tracks and rear and front wheel diameters. Commercially available rubber tracks $200 \times 72 \times 47,200 \mathrm{~mm}$ width and having an overall length of $3384 \mathrm{~mm}$ were chosen. Unfortunately these were not readily available in the shop and a pair of tracks equal but $230 \mathrm{~mm}$ wide were kindly delivered for free by the Italian company Minitop.

Wheels $504 \mathrm{~mm}$ in diameter were chosen for both rear and front wheels. By plotting the drawbar pull resulting from eq. (9) versus diameter ratio Df/Dr, for the same 3DCAD model, for different soil types, i.e. different values of Cone Index CI, we obtained a general increase in drawbar pull as diameter ratio increased, more sharp for lower values of cone index, i.e. looser soils. 
The same diameter for front and rear wheels seemed a good compromise between drawbar pull and simplicity: having only one type of wheel makes maintenance easier as wheels can be interchanged and stock simpler.

The value of $504 \mathrm{~mm}$ diameter was chosen after the design of wheels was completed. In fact, wheels need to engage the track working as sprockets. We have chosen to have 11 engaging lugs simply shaped as trapezium based cylinders.
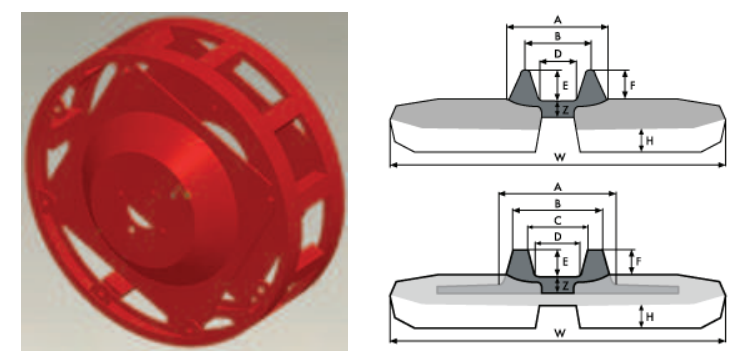

Fig.9. Sprocket wheel and track shape.

A refined analytical model was developed in second approximation, taking into account the presence of tracks instead of wheels.

In the first model the tractor unit has been treated as four wheel machine, and the effect of tracks has been considered generally as increasing the overall drawbar pull four times. In fact, the assumption of having only driven wheels at rear is not true anymore having both rear and front wheels contributing to traction as well as to rolling resistance.

Therefore eq. (10) can be used instead of eq. (4) to estimate the maximum drawbar pull the system is able to exert:

$$
\begin{gathered}
P_{\max }=H_{\max }-\left(\rho_{f} \cdot V_{f}+\rho_{r} \cdot V_{r}\right) \\
H_{\max }=2 A \cdot c+W \cdot \tan \phi
\end{gathered}
$$

Where, $H_{\max }$ is the maximum tractive force the system can exert when tracks are locked and is given by eq. (11). W is the total weight of the system, $\mathrm{A}$ is the area of contact with the ground of one track, c is soil cohesion and $\phi$ is the angle of soil internal friction. $\rho_{f}$ and $\rho_{r}$ can be obtained from tables (Macmillan, 2002) reporting coefficients of rolling resistance versus tyre diameter, considering the front wheels approaching an harder ground and the rear wheels a more loose soil. Vr and Vf are known once the soil tool interaction force is known in modulus (already known) and direction (depends on the shape of the ground processing tool), from equilibrium equations applied to the system constituted by the entire machine plus tool.

Modifying the power tiller by adding the new components will cause an increase in its weight. In general, adding extra weight and enlarging the ground contact area to a tractor is desirable, especially if no idlers are to be used to keep the track in contact with the ground (to keep the frame as simple as possible) and ballast may have to be used to improve weight distribution between the front and the rear of the track. Nevertheless, adding weight could 
cause to have the machine not slipping any more in lower gears before the engine gets stall. This is a form of protection as it limits the load on the transmission components: in most tractors the weight and tyres are such that in the lower gears the wheels will slip before the engine stalls, while in higher gears the opposite happens. Therefore, the maximum tractive force exerted by the machine when tracks are locked, and therefore $100 \%$ slippage occurs, was calculated and compared with the maximum force the engine can generate horizontally at wheel-soil contact. Equation (11) was used to determine the maximum tractive force for the power tiller weighing $480 \mathrm{~kg}$, employing the tracks chosen $230 \times 72 \times 47$ on soil having an angle of internal friction of $30^{\circ}$ as equal to $2716 \mathrm{~N}$. This doesn't take into account the contribution given by soil cohesion expressed by the first term of eq. (11) as it is negligible. The value obtained was compared to the force the power tiller can generate at wheel-ground contact, horizontally. This was calculated for the power tiller Pasquali purchased in Italy, having $7.5 \mathrm{~kW}$ power, 50 gear ratio in the first gear, $250 \mathrm{~mm}$ wheel radius, $1.1 \mathrm{~km} / \mathrm{h}$ speed in first gear as equal to $25000 \mathrm{~N}$. Therefore, in low gear, the engine should not stall.

The frame has to satisfy the requirements of supporting front wheels and tracks, supporting the ground processing tool and vegetation cutter tool and allowing remote control. The chassis of the power tiller Pasquali presents two mounting areas that can be exploited for supporting the frame, one at the back and one at the front of the chassis. The power tiller has no brakes, but presents a differential gear.

Two disk brakes, second-hand from old motorbikes, were employed to break the two driven wheels and allow remote steering by actuating them separately. This solution was chosen for its simplicity: disk brakes are available everywhere second hand, are cheap and only little adjustments had to be made to the existing structure to fix them to it. Fixtures allowing the mounting of the disc brakes on to the power tiller chassis were designed, realized and tested together with the control. They are made of aluminium.
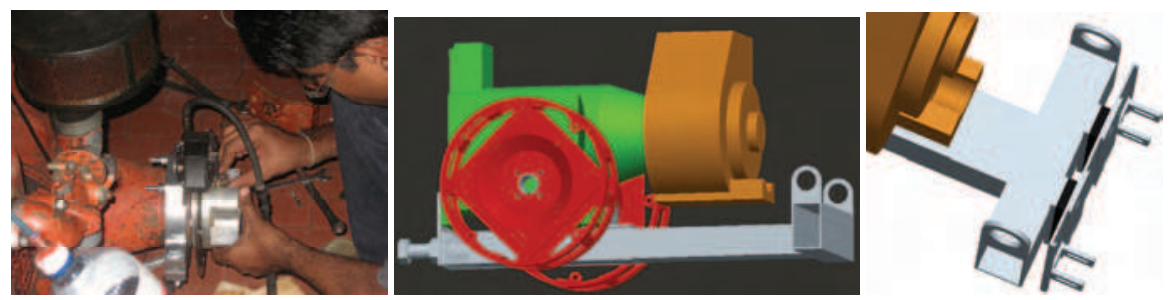

Fig. 10. Disc brake assembly; frame; frame-tools interface

Therefore, the idea of having a single frame supporting front wheels, tools and tensioning the track was pursued as the simplest.

The frame designed is represented in fig.10. and is characterized by being all made of steel standard profile, easy to build and to maintain as only welding of profiles available on the market is needed. It is constituted by a main fore - and aft frame member in the form of a rectangular hollow section fixed to the two mounting areas on the body of the tiller and extended forwards to the front axle member. On the same profile rearwards can be fit a ballast weight if necessary to improve the weight distribution. This main frame member has a second rectangular hollow section member sliding within it that carries the front axle. The rear end of this is located by a large screw at the rear of the tractor which is used to tension 
the tracks. The front stub axles each running in two bearings is carried on the front axle member attached to the second member mentioned above.

Although the conventional method of tightening crawler tracks is to individually spring load them with compression spring located within the track, this arrangement allowing for any difference in length of the tracks and also for vertical deformation of the tracks between the wheels when the track passes over a stone or local hump, it was considered not to be convenient to use in the present work. Instead we decided to tension the tracks by pushing on the front axle member, on which the front wheels are mounted through the screw at the rear of the machine. This design is simpler and provides a near rigid arrangement by treating both tracks in the same way.

Depending on the difference in length of the tracks and the evenness of the ground, this arrangement will probably be satisfactory for some time and allow a decision to be made as to whether the mechanically more complex arrangement proposed above is required for long term operation.

As the machine presents modular structure, the interface between the frame and the tools as to be very versatile. The interface designed, where either ground processing tool or vegetation cutter tool can be mounted is characterized by presenting sliding frames, where different mounting hinges can be inserted and fixed at the required height. It is connected to the main frame through three dumpers, aimed at reducing the impact of shock waves, due to the accidental explosion of a landmine by the front ground processing tool, to the power tiller structure.

\section{Ground Processing Tool}

The task of the machine is to process the ground in order to make demining activities with excavation tools easier for deminers. The ground processing tool has to smooth the soil up to the required depth of $100 \mathrm{~mm}$ never pushing mines deeper but possibly lifting them up. The requirements the ground processing tool has to satisfy therefore are to remove landmines from the lane where the machine is working and processing the soil at constant depth.

There are two possibilities for landmines disposal: collecting them or push them beside the machine. The first choice allows the work to be done all at once as no more verification or mine disposal is required after the machine has passed, but foresees also some complications: a sensor is needed to understand when a landmine has been found. Collecting more landmines in the same place can be dangerous as a big explosion could occur if an abrupt movement is done. The second choice of pushing mines beside is limited by the vegetation factor as if there is too much vegetation mines will be pushed in uncleared lanes and will not be visible. Nevertheless, we decided to implement it first as it is very simple and still practical when vegetation is not heavy.

The question of the form of the tool was a major aspect of the overall work and occupied a considerable portion of our time. There are few published precedents this aspect of the work although it has similarities to some tillage tools. There were three important implications in deciding the shape of the tool.

Weight transfer: most soil engaging tools involve a horizontal (draft) and vertical force. When the tool is mounted on the front of the tractor both of these forces, together with the weight of the tool, have the effect of transferring weight from the rear to the front of the 
tractor. These effects are generally undesirable (on a rear wheel drive tractor) and hence it is important that they do not become excessive.

Depth control: the requirement for good depth control is to avoid the tool working too shallow and missing mines or digging too deep and causing the tractor engine to stall or the tracks to slip. Mounting the tool on the tractor alone is likely to cause a variation in depth as the tractor pitches in the vertical longitudinal plane. Therefore we decided to fit a depth wheel running in the undisturbed soil ahead of the tool. This reduces the weight transfer effect of the tool and assists in depth control. It is in the form of a cage wheel on the assumption that this will suffer minimum damage if a mine were to explode under it.

Soil cutting and sieving: soil processing involves two aspects cutting the soil at the required depth and allowing it to pass through a sieve separating any object and mine bigger than a defined volume. The smallest dimension of the smallest mine present in the Vanni region (the Type72 AP landmine) is $40 \mathrm{~mm}$; therefore space between tines must be smaller than this. Various forms of tool were envisaged and a single blade to cut the soil with an attached sieve was chosen.

It is desirable, in the interests of simplicity, that the tool is formed from plane shapes. The simplest form of such a tool is therefore defined by two angles: a rake angle between the tool and the horizontal (ground) in the longitudinal vertical plane; a small rake angle allows the soil to flow up the tool in a thin sheet and so encourages sieving, and a side angle between the tool and the vertical longitudinal plane in the horizontal plane; a small side angle tends to cause the soil to be moved to the side and pass outside the passage of the tool width.

Therefore, to achieve mine disposal sideways, the original design used for developing a small cardboard and straws model (fig. 11) having rake angle equal to $20^{\circ}$ and side angle equal to $30^{\circ}$ was changed into a new design presenting a bigger side angle equal to $50^{\circ}$ and rake angle equal to $30^{\circ}$. The rake angle had to be increased to keep the distance of the tool tip from the frame relatively small.

The success of the tool in sieving soil and retaining or shedding mines depends on the form of the tool described above but also on the form of the sieve. Simplicity suggests that the form of the sieve members should either be in the plane of the sides of the tool, either parallel to the spine of the tool (effectively at the rake angle) or alternatively at the side angle (effectively horizontal). It would seem useful, in evaluative terms, to make one side of the sieve in one form and one in the other (fig.11). This would provide an immediate and obvious comparison of the two forms and guide future developments.

It is understood that some form of active movement of the tool would assist in breaking clods and clumps and so improve the sieving process. This however may not be necessary in sandy soil for which the initial form of tool is being developed. However it is likely to be needed for other heavier soils and for those which have been ripped with a plough.
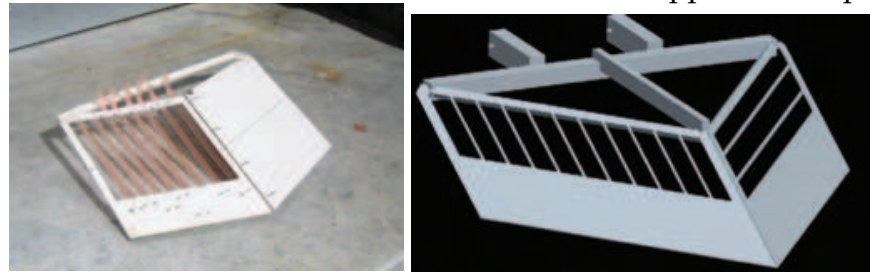

Fig. 11. First and second version of ground processing tool 
Various methods might be envisaged to provide active motion of the tool, the simplest being using a 'bumpy' wheel. A depth wheel which was non-round would induce a near vertical motion to the tip of the tool.

An arrangement providing a means of lifting the tool when it is needed and at the end of the lane would also be necessary to overcome the problem of turning the machine with the tool in the ground. Work on the ground processing tool has to be completed.

\section{Vegetation Cutter Tool}

The task of the vegetation cutting module is to cut the vegetation obstructing the passage of the machine. When vegetation is present and the module needs to be employed, deminers, following the machine to locate and pick up mines lifted up on soil surface by the ground processing tool, will firstly proceed to remove the vegetation cut by the machine with the light rake.

Vegetation of the Vanni region can be classified into three types: light, if only grass is present, medium if there is also bush and heavy, if there are palm trees. We would need to use the vegetation cutting module only in case of medium and high level vegetation. When palm trees are present, the task of the module is only to cut leafs, as palm tree is protected by Sri Lankan law.

The power tiller we are employing as tractor unit has $7.5 \mathrm{~kW}$ engine; due its limited capacity, energy consumed by the vegetation cutting module should be as low as possible. The other requirements the module has to meet are the general ones valid for the whole machine: it should be low-cost, easy to use and maintain, robust, made of few simple parts, easy to find on the local market, able to work in dusty and dirty environment at high temperatures.

Moreover, as it is supported by a frame on the front of the machine it should also be as light as possible. Generally, large machines using flails, tiller units or brush cutters (Koppetch, 2006) are employed for cutting vegetation in minefields. According to the general philosophy of the project and due to the small size of the power tiller, instead of analysing dedicated systems we looked into existing technologies for cutting vegetation available on the agricultural market. Those are of four types: string trimmers, lawnmowers, hammer knife mowers and cutter bars. Because of their ability to cut small bushes as well as grass, they large cutting width, low cost and low power absorbed, we have decided to employ cutter bars as cutting system. Moreover cutter bars present a high level of modularity. In fact, they are constituted by two identical knife bar sections mounted on two frames, one fixed and one moving. In the version available on the market, rotary movement of the power take off (pto) is transformed into linear sinusoidal movement of the upper moving bar thanks to an eccentric and a sliding joint. 

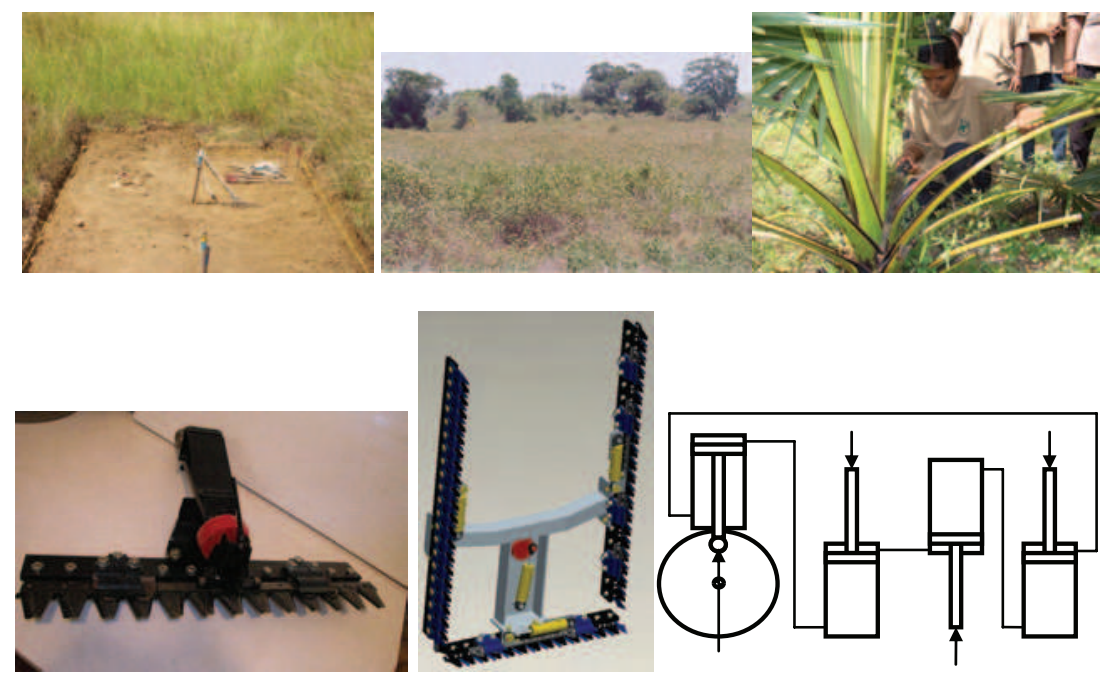

Fig. 12. Vanni region vegetation types: light, medium and heavy; cutter bar, vegetation cutting module architecture and layout of actuating cylinders

In order to create the space necessary for the machine to proceed when vegetation is thick, we have decided to employ three bars at the same time: one horizontal and two vertical. Vertical ones allow the machine to proceed in the bush and near to palm trees; they also cut tripwires if present. Different cutter bars with different lengths are available: they only differ for the number of teeth, the length of frames supporting the two knife bar sections and the number of components fixing bar sections to frames.

The overall number of components types is therefore limited, allowing simple maintenance even in the field. To repair the cutter few items per type of components are necessary to the operator, who can assembly and disassembly the whole system using only one wrench $17 \mathrm{~mm}$ size for nuts and a small hammer for pins fixing the mobile bar to its frame. Commercially available $650 \mathrm{~mm}$ and $1050 \mathrm{~mm}$ long bars are suitable to be mounted horizontally and vertically respectively.

Between possible actuating systems, a pneumatic one was preferred. In fact, it can produce high forces while occupying a reasonable compact space; it allows for flexible placement of components, is cheap, robust and easy to repair and maintain. To actuate the three cutter bars, double acting cylinders were chosen, providing both forward and backward stroke with the same force. To generate power it was chosen to employ another double acting cylinder actuated by an eccentric connected to the pto. This solution presents the advantage of being simpler, more robust and cheaper; moreover, it allows avoiding the use any type of control as the eccentric determines the correct motion law of the cylinder connected to it. Motion is transferred to cutting bars with no other components needed. After choosing the actuation type, the architecture of the actuation system was chosen. A simple and compact solution was chosen. All cylinders are identical: only one type needs to be bought and stockpiled for maintenance. Repair in the field is also easier because operators need only few components. Moreover it is modular, if two cylinders are disconnected the volume of the two remaining facing chambers is equal. This is particularly useful when palm trees are not 
present in the minefield and only grass is present. Detaching the two vertical cutter bars allows saving power and fuel. The frame chosen is made of steel and is shown in fig. 12 .

\section{Control Unit}

The control system has to allow the tractor unit to be operated remotely in forward motion with steering acting on the semi-axles. Generally power tillers are controlled manually by an operator walking behind them.

After having started the machine manually, while keeping clutch pressed, the gear is shifted and forward/backward motion selected. Then, the clutch can be released causing wheel to decouple and motion starts. The operator follows the machine adjusting the acceleration according to working needs. When direction needs to be changed, firstly the differential is actuated to allow non-synchronized movement of the wheels. Direction is manually changed acting on handles. When the power tiller is moving in proper direction the differential can be switched off to preserve the direction.

After having analysed manual operations, the features to be actuated by the control system were selected. All existing levers can be automated but changing direction, which is usually performed by the operator, rises up a problem. As a solution, external braking system constituted by the disc brakes was considered. Turning is therefore achieved in this way. When direction is not relevant the differential firstly is actuated. Then, when wheels can be moved in not coordinated way, one of the brakes can be applied decreasing the speed of the wheel. This causes the direction to change proportionally to the difference in wheels speed. After reaching the proper direction, the brake is released and differential switched off forcing synchronous motion. According to previous considerations, the features selected for actuation are shown in table 1 . Motion type analysis indicates that linear motion is needed mainly. In some cases actuation is needed in both movement directions in others one direction is passive. Deadlocks possibility should be regarded as source of further possible actuation problems. For actuation, pneumatic system was chosen having the following significant advantages in this application: natural linear motion, resistance to deadlocks, resistance to vibrations and contamination, big variety of actuators available.

The pneumatic system needs an air-compressor that will be mounted on board of the power tiller. Control system was designed accordingly to digital control system design Moore approach (Kostrzewski et al., 2007). Logic equations were implemented using Siemens Logo controller which is cheap and robust, allows for software based programming, conventional switches are not needed and extended communication features can be used.

\begin{tabular}{l|ll} 
Feature & Motion type & Actuator type \\
\hline Differential & $\begin{array}{l}\text { Angular and linear; linear easier to } \\
\text { apply; deadlocks during switching the } \\
\text { differential on } \\
\text { Linear motion, big force, no deadlocks, } \\
\text { one-side force needed } \\
\text { Linear motion, low force, position } \\
\text { holding }\end{array}$ & $\begin{array}{l}\text { Single-acting cylinder, } \\
\text { return stroke by spring }\end{array}$ \\
Acceleration & $\begin{array}{l}\text { Single-acting cylinder, } \\
\text { rinear motion, one-side force, no } \\
\text { deadlocks }\end{array}$ & $\begin{array}{l}\text { Double-acting cylinder } \\
\text { Single-acting cylinder, } \\
\text { return stroke by spring }\end{array}$
\end{tabular}

Table 1. Power tiller controlled features 

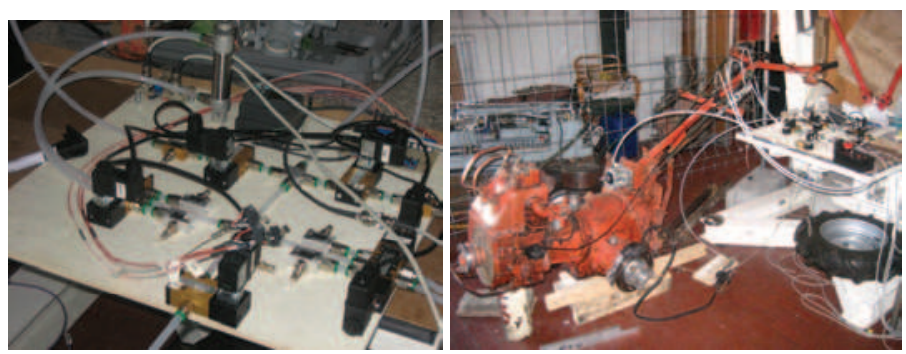

Fig. 13. Pictures of the valve bay and the control system assembled on the power tiller

\section{Conclusions and Further Work}

Considering the increasing consensus on the fact that mine action should be regarded as a development activity, there should be rapid change of the current approach. The paper summarises few topics in the domain and introduces a new integrated approach to the design of simpleffective demining technologies. The methodology is applied to the design of a simple modular machine for assisting mine removal through ground processing and vegetation cutting. The tractor unit is chosen in the agricultural machines domain (power tillers), so that to assure the full consistency with the local expertise and habits. Cost and sophistication minimisation is primary objective of the present project. The machine is equipped with a pneumatic remote control, versatile enough to be fit on almost every kind of power tiller.

The work on the machine is not completed yet, the complete design having to be finalised through FEM analyses, developed and assembled. The overall work on the first prototype currently at the University of Genova will end in October 2007. After proper tests, results, experience and lessons learnt will be used to re-design and develop a second prototype in Sri Lanka, based upon a slighter more powerful Chinese power tiller available on the local market. During November and December the author will work in the field together with deminers to finalize the project. If the civil conflict will impede it, the final prototype will be built in another country with similar characteristics to the Vanni region of Sri Lanka, like Jordan. All information regarding the project as test reports are freely available at the project website: http://www.dimec.unige.it/PMAR/demining/index.html

\section{Acknowledgments}

The research project presented has been undertaken by the author in the context of her doctoral studies. The work proposed has been discussed with many valuable people, whom she would like to thank for their support in terms of suggestions and material offered: prof. Ross Macmillan of the University of Melbourne, Andy Smith of AVS Mine Action Consultants, Luke Atkinson of NPA, Prof. Jayatissa of the University of Peradenya, Paolo Silingardi, Szymon Kostrzewski, Rusiru Dasantha, Jawaad Masood of University of Genova, Danilo Coppe of I.R.E., Andrea Pinza of Grillo, Giampiero Giacomino of Minitop, Giuliano Gori of GoGomma, Al Carruthers. 


\section{References}

Cepolina, E, (2007). Power tillers for Demining: Blast Test. International Journal of Advanced Robotic Systems, Vol.4, No.2, (June 2007) page numbers (253-1257), ISSN 1729-8806.

Cepolina, E. (2006). Power Tillers and Snails for Demining in Sri Lanka, Journal of Mine Action Vol.10, No.1, (August 2006) page numbers (76-79), ISSN 1533-9440.

Cepolina, E.; Bruschini, C. \& De Bruyn, K. (2004). Providing demining technology end-users need - $\quad$ Field Survey Results, EUDEM2 publication, http://www.eudem.vub.ac.be/files/FieldSurvey_Results_V1.0.0.pdf.

Filippino, E. (2005). Mine Action: Lessons and Challenges, GICHD, ISBN 2-88487-025-3, Geneva.

Hlady, S.; Bergeron, D. \& Gonzalez, R., (2006). Protecting vehicles from landmine blast, Defence R\&D Canada, US Army, Report

International Campaign to Ban Landmines (ICBL). (2006). Landmine Monitor Report, ICBL, ISBN 1-56432-287-4, USA.

Koppetch, K., (2006). Mechanical Demining Equipment Catalogue 2006, GICHD, ISBN: 288487-026-1, Geneva.

Kostrzewski, S.; Dasantha, R; Masood, J \& Cepolina, E. (2007). Portable mechatronic system for demining applications: control unit design and development, Proceedings of The Fourth International Symposium Humanitarian Demining 2007, Croatia, April 2007, Sibenik.

Kruger, I. \& Palmer, A. (1982). Effects on Scarifier Draft of Soil Moisture, Depth and Speed of Tillage, Proceedings of Conference on Agricultural Engineering, pp. 123-126, Armidale, 22-24 August 1982.

Macmillan, R. (2002).The Mechanic of Tractor - Implement Performance, University of Melbourne, Available from: http://www.eprints.unimelb.edu.au.

Naidoo, S. (2007). Background brief: Linking Mine Action to Development Cooperation (LMAD), GICHD, www.gichd.ch.

National Bank for Agriculture and Rural Development (NABARD) (2007). Indian National strategy, Farm Machinery, http:/ / www.nabard.org/modelbankprojects/farmmachinery.asp

Roth, B. (2006). Design Thinking, Proceedings of Machine Design and Research, pp. 1-5, ISSN 1006-2343, China, August 2006, Jixie Sheji yu Yanjiu.

Sachs, J. (2005). The End of Poverty, how can we make it happen in our lifetime, Penguin Press, ISBN 9780143036586, USA.

Salvi, M. \& Cepolina, E. (2005). Effects of the explosion of a Landmine on a Power tiller, Available from: http://www.dimec.unige.it/PMAR/demining/agenda_reports.html.

Wikipedia (2007). Two Wheel Tractor definition. 


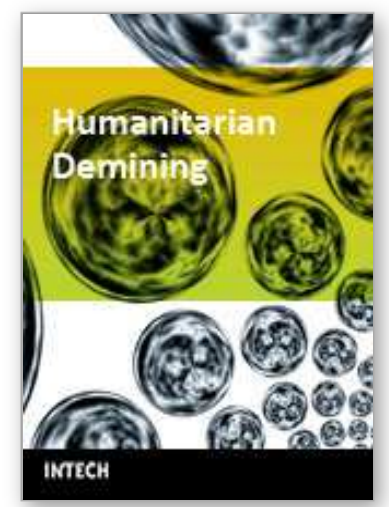

\author{
Humanitarian Demining \\ Edited by Maki K. Habib
}

ISBN 978-3-902613-11-0

Hard cover, 392 pages

Publisher I-Tech Education and Publishing

Published online 01, February, 2008

Published in print edition February, 2008

United Nation Department of Human Affairs (UNDHA) assesses that there are more than 100 million mines that are scattered across the world and pose significant hazards in more than 68 countries. The international Committee of the Red Cross (ICRC) estimates that the casualty rate from landmines currently exceeds 26,000 persons every year. It is estimated that more than 800 persons are killed and 1,200 maimed each month by landmines around the world. Humanitarian demining demands that all the landmines (especially AP mines) and ERW affecting the places where ordinary people live must be cleared, and their safety in areas that have been cleared must be guaranteed. Innovative solutions and technologies are required and hence this book is coming out to address and deal with the problems, difficulties, priorities, development of sensing and demining technologies and the technological and research challenges. This book reports on the state of the art research and development findings and results. The content of the book has been structured into three technical research sections with total of 16 chapters written by well recognized researchers in the field worldwide. The main topics of these three technical research sections are: Humanitarian Demining: the Technology and the Research Challenges (Chapters 1 and 2), Sensors and Detection Techniques for Humanitarian Demining (Chapters 3 to 8 ), and Robotics and Flexible Mechanisms for Humanitarian Demining respectively (Chapters 9 to 16$)$.

\title{
How to reference
}

In order to correctly reference this scholarly work, feel free to copy and paste the following:

Cepolina Emanuela Elisa (2008). Power Tillers for Demining in Sri Lanka: Participatory Design of Low-cost Technology, Humanitarian Demining, Maki K. Habib (Ed.), ISBN: 978-3-902613-11-0, InTech, Available from: http://www.intechopen.com/books/humanitarian_demining/power_tillers_for_demining_in_sri_lanka_participat ory_design_of_low-cost_technology

\section{INTECH}

open science | open minds

\section{InTech Europe}

University Campus STeP Ri

Slavka Krautzeka 83/A

51000 Rijeka, Croatia

Phone: +385 (51) 770447

Fax: +385 (51) 686166

\section{InTech China}

Unit 405, Office Block, Hotel Equatorial Shanghai

No.65, Yan An Road (West), Shanghai, 200040, China 中国上海市延安西路65号上海国际贵都大饭店办公楼 405 单元

Phone: +86-21-62489820

Fax: +86-21-62489821 
www.intechopen.com 
(C) 2008 The Author(s). Licensee IntechOpen. This chapter is distributed under the terms of the Creative Commons Attribution-NonCommercialShareAlike-3.0 License, which permits use, distribution and reproduction for non-commercial purposes, provided the original is properly cited and derivative works building on this content are distributed under the same license. 